\title{
Length variation of chloroplast simple sequence repeats in the genus Eucalyptus L'Hér.
}

\author{
Sonu Kumar \& Asheesh Shanker* \\ Department of Bioinformatics, Central University of South Bihar, Gaya 824 236, India \\ *Email: ashomics@gmail.com
}

\author{
ARTICLE HISTORY \\ Received: 12 February 2020 \\ Accepted: 18 April 2020 \\ Published: 01 July 2020

\section{KEYWORDS} \\ Eucalyptus \\ Chloroplast \\ Simple sequence repeats \\ Polymorphism \\ Transferability
}

\begin{abstract}
Eucalyptus L'Hér. is an economically important genus of plants with several environmental significances and great industrial advantages. To accelerate breeding and conservation studies, efforts on molecular breeding and molecular genetic analysis are underway in the genus Eucalyptus. Despite these efforts, no sufficient information is available about common, polymorphic and unique chloroplast simple sequence repeats (cpSSRs) in the genus Eucalyptus. . These repeats consist of 1-6 nucleotides and play important role in the development of molecular markers, genetic mapping and plant breeding. In the present study, a total of 920 cpSSRs were detected and length variation of cpSSRs analysed between each pair of species among 31 chloroplast genome sequences of the genus Eucalyptus. Additionally, cross species transferability of common and polymorphic cpSSRs were also observed. The common, unique and putative polymorphic cpSSRs analysed in this study can be used for species identification and genetic diversity studies of Eucalyptus.
\end{abstract}

\section{Introduction}

Eucalyptus is a diverse genus of plants and world's driving industrial plantation species with multipurpose utility. It allows a great variety of uses with profitable and sustainable applications (1). Most of the Eucalyptus plantations all over the world are intended for paper, pulp and veneer production (2). Additionally, Eucalyptus has greater forest productivity and several environmental and medicinal significance (3-5). Efforts on molecular breeding and molecular genetic analysis are underway in Eucalyptus to accelerate breeding and conservation. Various molecular markers including restriction fragment length polymorphism (RFLP; 6), random-amplified polymorphic DNA (RAPD; 7) and amplified fragment length polymorphism (AFLP; 8) have been used in Eucalyptus for a variety of purposes. Currently, simple sequence repeats (SSRs) are widely applied molecular markers in genetic studies $(1,9,10)$.

SSRs also known as microsatellites are tandem repetitions of short motifs of 1-6 nucleotides (11). These repeats are found in coding and non-coding regions of prokaryotic and eukaryotic genomes (12, 13). SSRs are broadly used genetic markers due to its codominant and highly reproducible nature. Along with phylogenetic studies, organelle genomes have also been used to identify SSRs (14-20).

Earlier, it was reported that 4 highly polymorphic genomic SSRs were characterized in E. nitens and observed 50\% conservation of SSR loci in subgenera Symphyomyrtus and Monocalyptus (9). Complete chloroplast genome sequence of $E$. globulus was used to develop 35 cpSSRs, in which 10 cpSSR showed intraspecific polymorphism (21). Genetic diversity among 19 geographically defined E. urophylla populations was investigated using 12 nuclear SSR markers (22). Transferability was observed from their target species to closely related species $(23,24)$. In a study there developed 8 highly polymorphic genomic SSR loci for E. leucoxylon (25). EST-SSRs were also developed in many Eucalyptus spp (26 -28). There are reports on the identification of genetic markers in three Eucalyptus spp (E. camaldulensis, E. tereticornis and $E$. grandis) using high throughput method (29). Recently, distribution and organization of cpSSRs in 31 Eucalyptus species was observed (30).

(c) Kumar \& Shanker (2020). This is an open-access article distributed under the terms of the Creative Commons Attribution License, which permits unrestricted use, distribution, and reproduction in any medium, provided the original author and source are credited (https://creativecommons.org/licenses/by/4.0/).

To cite this article: Kumar S, Shanker A. Length variation of chloroplast simple sequence repeats in the genus Eucalyptus L'Hér. Plant Science Today. 2020;7(3):353359. https://doi.org/10.14719/pst.2020.7.3.750 
Apart from these efforts on SSRs have also been focused to identify putative polymorphic microsatellites from sequence data $(13,31,32)$. These polymorphic SSRs have been differentiated from monomorphic SSRs by length variation between motifs. Recently, common and unique SSRs have also been identified in several species $(13,19,20)$. Moreover, transferability of SSRs was observed between Croton floribundus and Croton urucurana (Euphorbiaceae;31) and genus Lasiodiplodia and Neofusicoccum (34).

Despite these efforts, no sufficient information is available about common, unique and putative polymorphic SSRs in chloroplast genomes (cpgenomes) of genus Eucalyptus. Therefore, the present bioinformatics study designed to analyse common, unique and putative polymorphic SSRs in complete chloroplast genome sequences of genus Eucalyptus.

\section{Materials and Methods}

\section{Identification of common, unique and polymorphic cpSSRs}

Complete chloroplast genome sequences of genus Eucalyptus were mined with the help of Microsatellite identification tool (MISA; http://pgrc.ipk-gatersleben.de/misa/misa.html) to detect common, unique and polymorphic cpSSRs. The minimum repeat size of $\geq 12$ for mono-, $\geq 6$ for di-, $\geq 4$ for tri-, $\geq 3$ for tetra-, penta- and hexa-nucleotide repeats was considered. The maximum interruption between two SSRs was taken as zero. A list of mined chloroplast genome sequences of genus Eucalyptus with their genome size and sequence accession number is given in Table 1.

Common, unique and putative polymorphic cpSSRs were detected using a recently developed methodology $(13,19)$. Briefly, identical repeating units with equal and varying length, showing significant similarity of flanking regions across the species, were considered as common and polymorphic SSRs respectively. Other repeating units and identical repeating units with no significant match of flanking regions across the species were considered as unique SSRs. A flowchart of the methodology used is shown in Fig. 1. Moreover, common and putative polymorphic cpSSRs with reference to chloroplast genome of E. globulus were illustrated using MapChart software (35).

\section{Electronic PCR and gel simulation}

The PCR primer pairs for selected common and polymorphic cpSSRs (with 200 nucleotides flanking region from both upstream and downstream regions of SSRs) were designed with default parameters (GC content minimum 30\% and maximum 70\% melting temperature minimum 57 and maximum 62 and PCR product size) using online Primer3 tool (http://bioinfo.ut.ee/primer3/; 36).

Electronic PCR with designed primer pairs were carried out to check PCR product and cross-species transferability of cpSSRs among the genus Eucalyptus using simulated gel electrophoresis tool SPCR (http:// moleco.sjtu.edu.cn/spcr; 37). The threshold values 0.9 were set to upstream information coefficient $\left(\mathrm{I}_{\mathrm{up}}\right)$, downstream information coefficient $\left(\mathrm{I}_{\mathrm{dn}}\right)$, and product amplification coefficient $\left(\mathrm{P}_{\mathrm{a}}\right)$.

\section{Results and Discussion}

\section{Common, unique and polymorphic cpSSRs in genus Eucalyptus}

In this study, 920 perfect cpSSRs were mined to analyse common, unique and polymorphic in Eucalyptus species. A total of 34 repeat units were detected which have distributed over the chloroplast genome sequence of genus Eucalyptus, in which 6 (19.35\%) identical repeat units were found with varying length and 15 (48.38\%) with same length. Additionally, 13 (41.93\%) repeat units were observed as completely unique that were not found in the other cp-genomes. List of SSR motifs identified in cpgenomes of Eucalyptus species along with their frequency are presented in Table 2.

Mono-nucleotide motifs $\mathrm{A} / \mathrm{T}$, di-nucleotide motif AT, tri-nucleotide motif TTA, and tetra-nucleotide motifs ATAA/TTTC showed length polymorphism among the chloroplast cp-genomes of genus Eucalyptus. Additionally, 41 unique cpSSRs were observed on the basis of reciprocal BLAST search among genus Eucalyptus including 13 repeat units identified only in a particular species (supplementary file 1).

Identified repeating units were not equally present in all cp-genomes of genus Eucalyptus, therefore, the frequency of common and putative polymorphic cpSSRs varied between species. Previously, distribution and organization of cpSSRs were observed in Eucalyptus spp (30), however, the information about length variation of cpSSRs between species was not explored.

The variation in frequency of common and polymorphic cpSSRs between species was in conformity with genus Arabidopsis (19). Frequency of common, putative polymorphic and unique cpSSRs identified between species is shown in Supplementary table 1. Details of identified putative polymorphic and common cpSSRs for each species of Eucalyptus considered are given in supplementary file 2 and partially illustrated with reference to $E$. globulus in Fig. 2.

\section{Transferability of common and polymorphic cpSSRs in genus Eucalyptus}

E. globulus was considered as reference species to design PCR primer pairs and to in silico amplify PCR product. Details of designed primer pairs of cPSSRs motif, their length, start-end position, forward/reverse primer sequences, primer length, annealing temperature, GC content and product size are presented in Table 3 . There are reports on the transferability of SSRs within a genus can vary (38). In the present study, most of the cpSSRs primer pairs from reference species showed higher transferability rate, ranged from $93.54 \%$ to $100 \%$, among the genera. This is due to higher conservation of chloroplast genome sequences in different species of Eucalyptus. 
Table 1. List of chloroplast genomes of Eucalyptus along with their sequence accession number

\begin{tabular}{|c|c|c|c|c|c|}
\hline Sl. No. & Organism & Abr & Size $(\mathrm{Kb})$ & Accession No. & References \\
\hline 1. & Eucalyptus aromaphloia & $E a$ & 160.149 & NC_022396.1 & (41) \\
\hline 2. & Eucalyptus baxteri & $E b$ & 160.032 & NC_022382.1 & (41) \\
\hline 3. & Eucalyptus camaldulensis & $E c a$ & 160.164 & NC_022398.1 & $(41)$ \\
\hline 4. & Eucalyptus cladocalyx & $E c l$ & 160.213 & NC_022394.1 & (41) \\
\hline 5. & Eucalyptus cloeziana & $E c O$ & 160.015 & NC_022388.1 & (41) \\
\hline 6. & Eucalyptus curtisii & $E c u$ & 160.038 & NC_022391.1 & (41) \\
\hline 7. & Eucalyptus deglupta & $E d g$ & 160.177 & NC_022399.1 & (41) \\
\hline 8. & Eucalyptus delegatensis & $E d l$ & 159.724 & NC_022380.1 & (41) \\
\hline 9. & Eucalyptus diversicolor & $E d c$ & 160.214 & NC_022402.1 & (41) \\
\hline 10. & Eucalyptus diversifolia & $E d f$ & 159.954 & NC_022383.1 & (41) \\
\hline 11. & Eucalyptus elata & Eel & 159.899 & NC_022385.1 & (41) \\
\hline 12. & Eucalyptus erythrocorys & Eer & 159.742 & NC_022406.1 & (41) \\
\hline 13. & Eucalyptus globulus & $E g l$ & 160.286 & NC_008115.1 & $(42)$ \\
\hline 14. & Eucalyptus grandis & Egr & 160.137 & NC_014570.1 & (43) \\
\hline 15. & Eucalyptus guilfoylei & $E g u$ & 160.520 & NC_022405.1 & (41) \\
\hline 16. & Eucalyptus marginata & Ema & 160.076 & NC_022390.1 & (41) \\
\hline 17. & Eucalyptus melliodora & Eme & 160.386 & NC_022392.1 & (41) \\
\hline 18. & Eucalyptus microcorys & Emi & 160.225 & NC_022404.1 & (41) \\
\hline 19. & Eucalyptus nitens & $E n$ & 160.271 & NC_022395.1 & (41) \\
\hline 20. & Eucalyptus obliqua & Eo & 159.527 & NC_022378.1 & (41) \\
\hline 21. & Eucalyptus patens & Epa & 160.187 & NC_022389.1 & (41) \\
\hline 22. & Eucalyptus polybractea & Epo & 160.268 & NC_022393.1 & (41) \\
\hline 23. & Eucalyptus radiata & Era & 159.529 & NC_022379.1 & (41) \\
\hline 24. & Eucalyptus regnans & Ere & 160.031 & NC_022386.1 & (41) \\
\hline 25. & Eucalyptus saligna & Es & 160.015 & NC_022397.1 & (41) \\
\hline 26. & Eucalyptus salmonophloia & $E s a$ & 160.413 & NC_022403.1 & (41) \\
\hline 27. & Eucalyptus sieberi & Esi & 159.985 & NC_022384.1 & (41) \\
\hline 28. & Eucalyptus spathulata & $E s p$ & 161.071 & NC_022400.1 & (41) \\
\hline 29. & Eucalyptus torquata & $E t$ & 160.223 & NC_022401.1 & (41) \\
\hline 30. & Eucalyptus umbra & $E u$ & 159.576 & NC_022387.1 & (41) \\
\hline 31. & Eucalyptus verrucata & $E v$ & 160.109 & NC_022381.1 & (41) \\
\hline
\end{tabular}

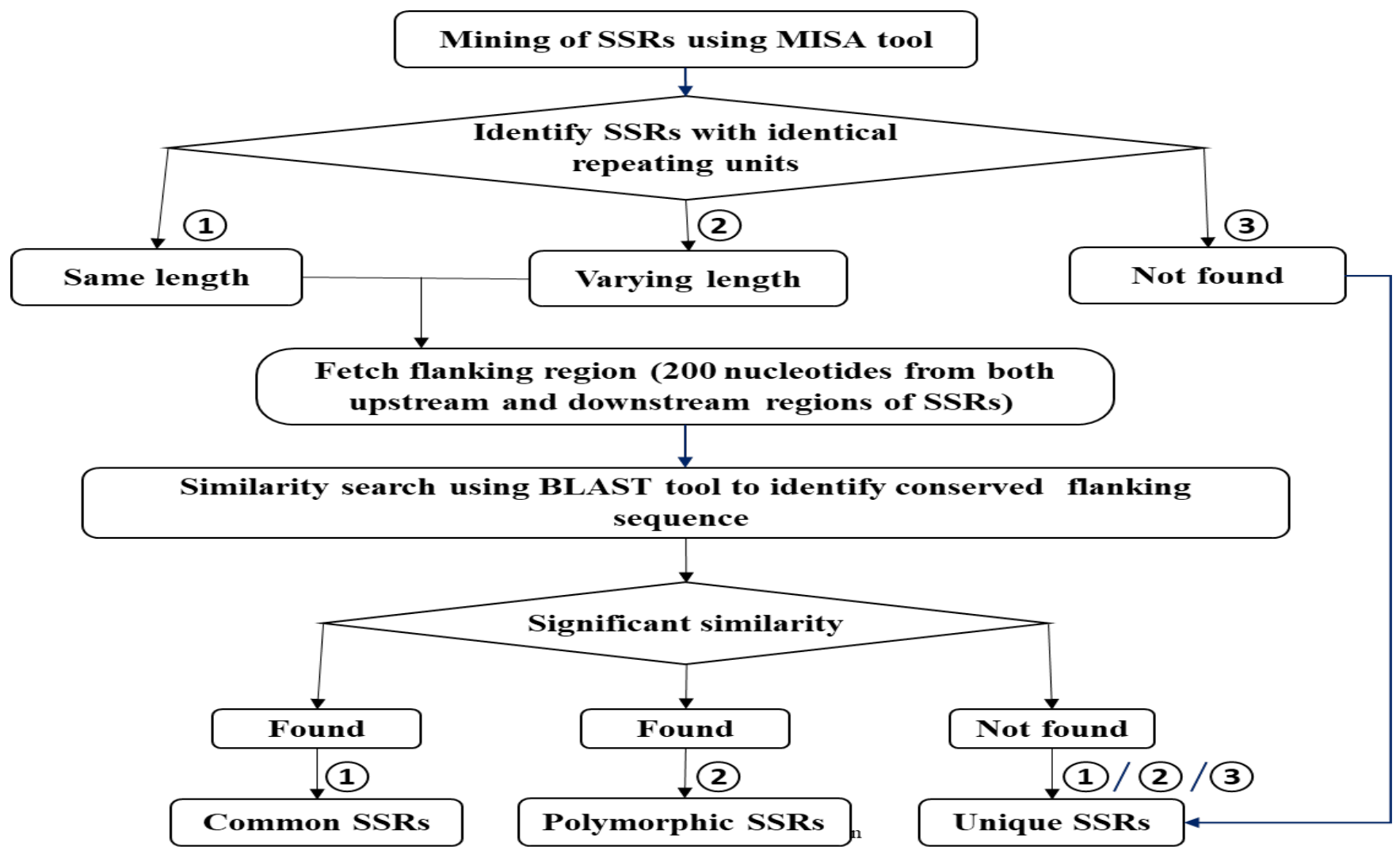

Fig. 1. Flowchart to identify common, unique and putative polymorphic SSRs. 
Table 2. List of SSR motifs identified in chloroplast genomes of Eucalyptus species along with their frequency.

\begin{tabular}{|c|c|c|c|}
\hline Sl. No. & SSR motif & No. of species & $\begin{array}{l}\text { Frequency } \\
\text { in genomes }\end{array}$ \\
\hline \multicolumn{4}{|c|}{ Identical repeating units with varying length } \\
\hline 1. & $\mathrm{~A}$ & 31 & 209 \\
\hline 2. & AT & 15 & 16 \\
\hline 3. & ATAA & 30 & 30 \\
\hline 4. & $\mathrm{~T}$ & 31 & 182 \\
\hline 5. & TTA & 19 & 19 \\
\hline 6. & TTTC & 31 & 61 \\
\hline \multicolumn{4}{|c|}{ Identical repeating units with same length } \\
\hline 1. & AAATG & 5 & 5 \\
\hline 2. & AAT & 3 & 3 \\
\hline 3. & AATA & 31 & 32 \\
\hline 4. & ATAG & 31 & 58 \\
\hline 5. & ATT & 27 & 28 \\
\hline 6. & ATTA & 30 & 45 \\
\hline 7. & ATTT & 26 & 27 \\
\hline 8. & СTT & 31 & 31 \\
\hline 9. & CTTG & 31 & 31 \\
\hline 10. & GAA & 30 & 30 \\
\hline 11. & GATA & 3 & 3 \\
\hline 12. & TAAG & 31 & 31 \\
\hline 13. & TAAT & 20 & 35 \\
\hline 14. & TATTT & 2 & 2 \\
\hline 15. & TTAA & 29 & 29 \\
\hline \multicolumn{4}{|c|}{ Unique repeating units } \\
\hline 1. & AAAT & 1 & 1 \\
\hline 2. & AATT & 1 & 1 \\
\hline 3. & CCTGAG & 1 & 1 \\
\hline 4. & CTATA & 1 & 1 \\
\hline 5. & СTTT & 1 & 1 \\
\hline 6. & $\mathrm{G}$ & 1 & 1 \\
\hline 7. & GAAAGG & 1 & 1 \\
\hline 8. & GGCAT & 1 & 1 \\
\hline 9. & TAT & 1 & 1 \\
\hline 10. & TATT & 1 & 1 \\
\hline 11. & TATTC & 1 & 1 \\
\hline 12. & TTC & 1 & 1 \\
\hline 13. & TTCCAT & 1 & 1 \\
\hline
\end{tabular}

Putative polymorphic cpSSR motifs, with length variation, $\mathrm{A} / \mathrm{T}$ showed $96.77 \%$ transferability rate among genus Eucalyptus (Fig. 3). Motif A was not amplified in E. cloeziana and E. erythrocorys, whereas motif T was not amplified in E. obliqua and E. radiata.

Among common cpSSRs, PCR amplification of same length motifs AATA (100\%) showed higher transferability rate followed by GAA (93.54\%) among Eucalyptus (Fig. 4). Motif GAA was not amplified in $E$. diversicolor and $E$. marginata, whereas, AATA showed transferability with every species among the genus Eucalyptus.

Earlier, many of the SSR loci isolated from $E$. grandis and $E$. urophylla were cross amplified with other species of Eucalyptus (39). Gene-homologous SSRs designed for E. gomphocephala were successfully transferred to $E$. marginata, $E$. camaldulensis and E. victrix (40). The present work showed higher transferability in comparison to four nuclear SSRs (50\%) from E. nitine to sub genera Symphyomyrtus and Monocalyptus (9). Moreover, 60 primer pairs were developed and virtually amplified among genus Eucalyptus displayed interspecific polymorphism (30). Recently, 12 and 11 markers of Lasiodiplodia mahajangana and Neofusicoccum parvum tested for length variation and high transferability of the developed markers were observed (34).

\section{Common and polymorphic cpSSRs with their Loci}

\section{E. globulus}

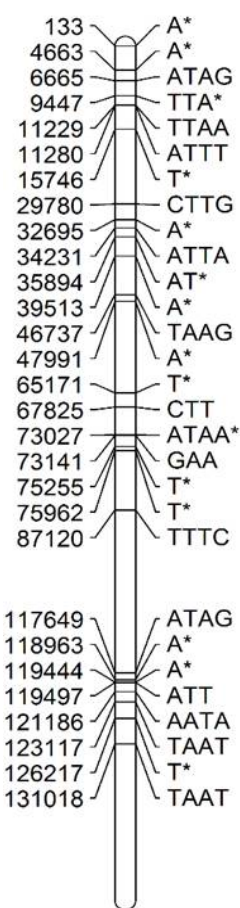

\section{E. aromaphloia}

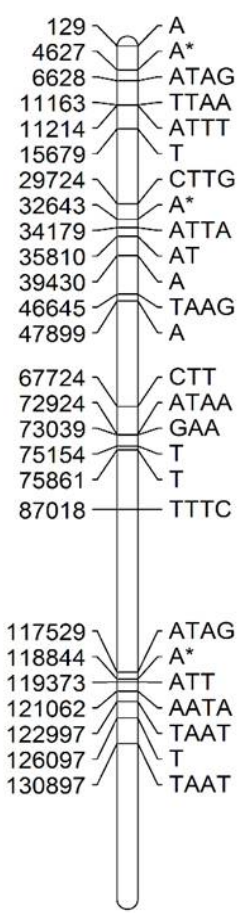

E. baxteri

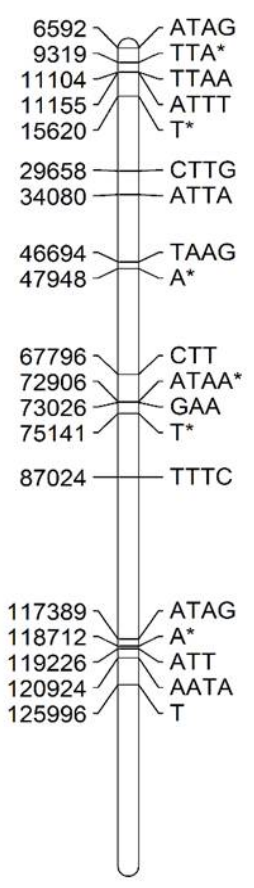

E. camaldulensis

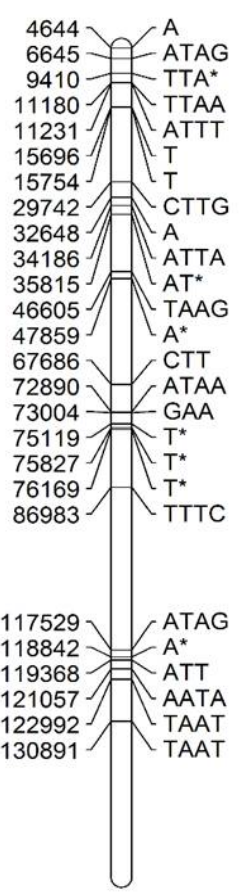

\section{E. cladocalyx}

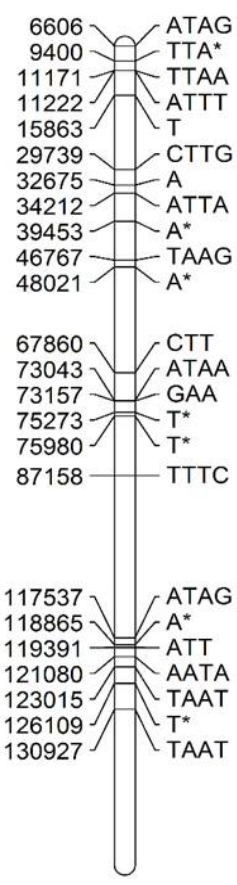

\section{E. cloeziana}

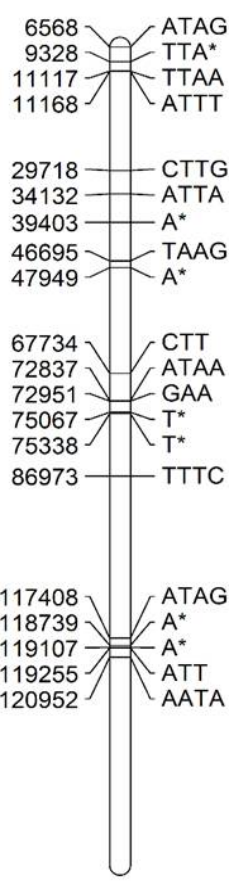

Fig. 2. Loci of common and polymorphic (indicated with *) cpSSRs along with their motif and start position between Eucalyptus globulus, as reference and other Eucalyptus spp. Organisms' abbreviations are given in Table 1. 
Table 3. Information of SSR motifs and primers used for in silico PCR

\begin{tabular}{|c|c|c|c|c|c|c|c|c|}
\hline \multicolumn{9}{|c|}{ Motifs with varying length among genome } \\
\hline $\begin{array}{l}\text { Sl. } \\
\text { No. }\end{array}$ & Motif & $\begin{array}{l}\text { Motif } \\
\text { Length }\end{array}$ & Star/ End & Forward / Reverse Primer & Primer Length (bp) & Temp & GC \% & $\begin{array}{l}\text { Product } \\
\text { Size }\end{array}$ \\
\hline 1. & $\mathrm{~A}$ & 13 & $\begin{array}{l}133 \\
145\end{array}$ & $\begin{array}{l}\text { AATCCACTGCCTTGATCCAC } \\
\text { GAAAGGTTATAATTTTCTGCTTCTTC }\end{array}$ & $\begin{array}{l}20 \\
26\end{array}$ & $\begin{array}{l}59.93 \\
57.48\end{array}$ & $\begin{array}{l}50.00 \\
30.77\end{array}$ & 227 \\
\hline 2. & $\mathrm{~T}$ & 12 & $\begin{array}{l}15746 \\
15757\end{array}$ & $\begin{array}{l}\text { CGTTCTGCTTGGCCCATTTAATTT } \\
\text { AGGTCGAATAATTGAATAGCA }\end{array}$ & $\begin{array}{l}25 \\
20\end{array}$ & $\begin{array}{l}60.68 \\
59.08\end{array}$ & $\begin{array}{l}36.00 \\
40.00\end{array}$ & 246 \\
\hline \multicolumn{9}{|c|}{ Motifs with same length among genome } \\
\hline 2. & GAA & 12 & $\begin{array}{l}73141 \\
73152\end{array}$ & $\begin{array}{l}\text { CCCAAATAAAAATCCGAACTCA } \\
\text { ATGGAGTTCGCTGGAGAATG }\end{array}$ & $\begin{array}{l}22 \\
20\end{array}$ & $\begin{array}{l}60.17 \\
60.22 \\
\end{array}$ & $\begin{array}{l}36.00 \\
36.50 \\
\end{array}$ & 203 \\
\hline
\end{tabular}



Fig. 3. In silico transferability of cpSSRs with varying length motifs (a) A and (b) T. Organisms' abbreviations are given in Table 1.

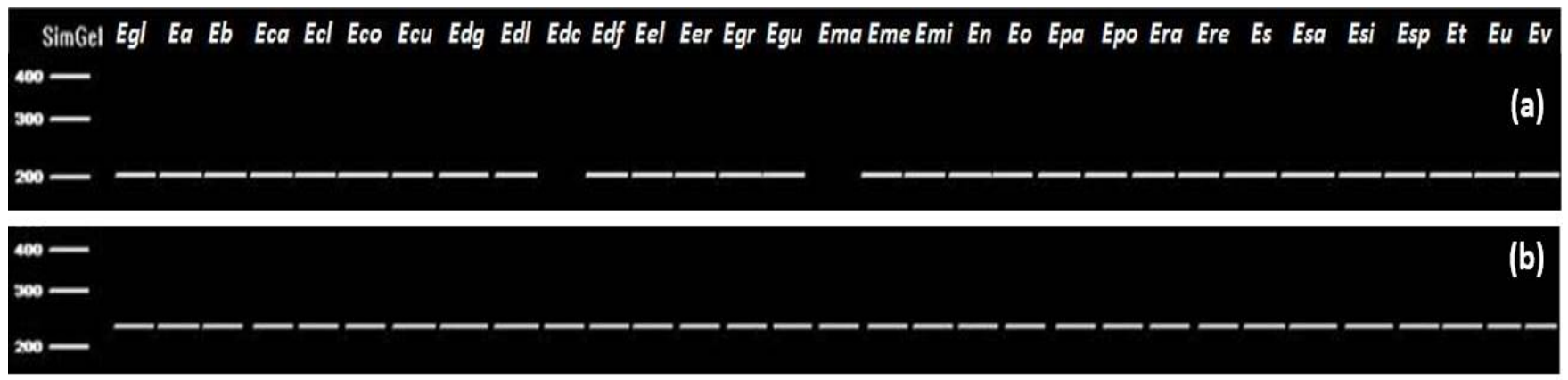

Fig. 4. In silico transferability of cpSSRs with same length motifs, (a) GAA and (b) AATA. Organisms' abbreviations are given in Table 1.

\section{Conclusion}

Distribution of common, unique and polymorphic cpSSRs were successfully analyzed among the genus Eucalyptus. Moreover, cross-species transferability of selected common and putative polymorphic cpSSRs were studied among genus Eucalyptus. The present study will play an important role in species identification, phylogeny, genetic diversity studies, genetic mapping etc. and will surely enhance the utility and potential of cpSSRs in Eucalyptus and other related genera.

\section{Acknowledgement}

SK is thankful to University Grants Commission (UGC), New Delhi, India to provide financial support in the form of Rajiv Gandhi National Fellowship.

\section{Authors' contributions}

SK performed the work and drafted the manuscript. AS designed the study framework and helped in the analysis of the data generated.

\section{Conflicts of interests}

The authors declare that they do not have any conflict of interest.

\section{Supplementary files}

Supplementary File 1: Details of identified unique cpSSRs among genus Eucalyptus.

Supplementary File 2: Details of identified putative polymorphic and common cpSSRs for each species of Eucalyptus.

Supplementary Table 1: Frequency of common, unique $(U)$, and putative polymorphic (bold) cpSSRs identified in genus Eucalyptus. Organisms' abbreviations are given in Table 1.

Supplementary Fig. 1: Loci of common and polymorphic (indicated with ${ }^{*}$ ) cpSSRs (with their start position) between reference (E. globulus) and other species. 


\section{References}

1. Sumathi M, Yasodha R. Microsatellite resources of Eucalyptus: current status and future perspectives. Bot Stud. 2014;55:73. https://doi.org/10.1186/s40529-014-0073-3

2. Luo J, Arnold R, Ren S, Jiang Y, Lu W, Peng Y, Xie Y. Veneer grades recoveries and values from 5-year-old Eucalyp clones. Ann Forest $\quad$ Sci. 2013;70:417-28. https://doi.org/10.1007/s13595-013-0268-x

3. Ahlem S, Khaled H, Wafa M, Sofiane B, Mohamed D and JeanClaude M. Oral administration of Eucalyptus globulus extract reduces the alloxan-induced oxidative stress in rats. Chem Biol Interact. 2009 ;

https://doi.org/10.1016/j.cbi.2009.06.006

181:71-76.

4. Dessie G. Eucalyptus in East Africa: socio-economic and environmental issues. IWMI; 2011; H043946

5. Eidi A, Eidi M, Givianrad MH, Abaspour N. Hypolipidemic effects of alcoholic extract of Eucalyptus (Eucalyptus globulus Labill) leaves on diabetic and non-diabetic rats. J Diabetes Metab Disord. 2009;8:13

6. Steane DA, West AK, Potts BM, Ovenden JR, Reid JB. Restriction fragment length polymorphisms in chloroplast DNA from six species of Eucalyptus. Aust J Bot. 1991;39:399-414. https://doi.org/10.1071/BT9910399

7. Keil M, Griffin AR. Use of random amplified polymorphic DNA (RAPD) markers in the discrimination and verification of genotypes in Eucalyptus. Theor Appl Genet. 1994;89:442-50. https://doi.org/10.1007/BF00225379

8. Marques CM, Araujo JA, Ferreira JG, Whetten R, O'malley DM, Liu BH, Sederoff R. AFLP genetic maps of Eucalyptus globulus and E. tereticornis. Theor Appl Genet. 1998;96:727-37. https://doi.org/10.1007/s001220050795

9. Byrne M, Marquezgarcia MI, Uren T, Smith DS, Moran GF. Conservation and genetic diversity of microsatellite loci in the genus Eucalyptus. Aust J Bot. 1996;44:331-41. https://doi.org/10.1071/BT9960331

10. Acuña CV, Fernandez P, Villalba PV, García MN, Hopp HE, Poltri SNM. Discovery validation and in silico functional characterization of EST-SSR markers in Eucalyptus globulus. Tree Genet Genomes. 2012;8:289-301. https://doi.org/10.1007/s11295-011-0440-0

11. Shanker A. Identification of microsatellites in chloroplast genome of Anthoceros formosae. Arch Bryol. 2013;191:1-6

12. Shanker A, Bhargava A, Bajpai R, Singh S, Srivastava S, Sharma V. Bioinformatically mined simple sequence repeats in UniGene of Citrus sinensis. Sci Hort. 2007;113:353-61. https://doi.org/10.1016/j.scienta.2007.04.011

13. Kabra R, Kapil A, Attarwala K, Rai PK, Shanker A. Identification of common unique and polymorphic microsatellites among 73 cyanobacterial genomes. World J Microbiol Biotechnol. 2016;32:71. https://doi.org/10.1007/s11274-016-2061-0

14. Shanker A, Sharma V, Daniell H. Phylogenomic evidence of bryophytes' monophyly using complete and incomplete data sets from chloroplast proteomes. J Plant Biochem Biot. 2011; 20:288-92. https://doi.org/10.1007/s13562-011-0054-5

15. Shanker A. Combined data from chloroplast and mitochondrial genome sequences showed paraphyly of bryophytes. Arch Bryol. 2013;171:1-9

16. Shanker A. Inference of bryophytes paraphyly using mitochondrial genomes. Arch Bryol. 2013;165:1-5

17. Kapil A, Rai PK, Shanker A. ChloroSSRdb: a repository of perfect and imperfect chloroplastic simple sequence repeats (cpSSRs) of green plants. Database. 2014;bau107. https://doi.org/10.1093/database/bau107

18. Kumar M, Kapil A, Shanker A. MitoSatPlant: mitochondrial microsatellites database of viridiplantae. Mitochondrion. 2014;19:334-37. https://doi.org/10.1016/j.mito.2014.02.002

19. Kumar S, Shanker A. Common unique and polymorphic simple sequence repeats in chloroplast genomes of genus Arabidopsis. Vegetos. 2018;31(special):125-31. https://doi.org/10.5958/22294473.2018.00043.5
20. Kumar S, Shanker A. Analysis of microsatellites in mitochondrial genome of Aneura pinguis (L.) Dumort. In: Afroz Alam, editor. Recent Advances in Botanical Science: Contemporary Research on Bryophytes 2020 pp. 20-37. Bentham Science Publishers Pte. Ltd. Singapore. https://doi.org/10.2174/9789811433788120010011

21. Steane DA, Jones RC, Vaillancourt RE. A set of chloroplast microsatellite primers for Eucalyptus (Myrtaceae). Mol Ecol Resour. 2005; 5:538-41. https://doi.org/10.1111/j.1471 8286.2005.00981.x

22. Payn KG, Dvorak WS, Janse BJ, Myburg AA. Microsatellite diversity and genetic structure of the commercially important tropical tree species Eucalyptus urophylla endemic to seven islands in eastern Indonesia. Tree Genet Genomes. 2008;4:519 30. https://doi.org/10.1007/s11295-007-0128-7

23. Brondani RPV, Brondani C, Tarchini R, Grattapaglia D. Development characterization and mapping of microsatellite markers in Eucalyptus grandis and E urophylla. Theor App Genet. 1998; 97:816-27. https://doi.org/10.1007/s001220050961

24. Brondani R, Brondani C, Grattapaglia D. Towards a genus-wide reference linkage map for Eucalyptus based exclusively on highly informative microsatellite markers. Mol Genet Genomics. 2002;267:338-47. https://doi.org/10.1007/s00438-002 0665-6

25. Ottewell KM, Donnellan SC, Moran GF, Paton DC. Multiplexed microsatellite markers for the genetic analysis of Eucalyptus leucoxylon (Myrtaceae) and their utility for ecological and breeding studies in other Eucalyptus species. J Hered. 2005; 96:445-51. https://doi.org/10.1093/jhered/esi057

26. Ceresini PC, Silva CLSP, Missio RF, Souza EC, Fischer CN, Guillherme IR, Gregorio I, Silva EHTD, Cicarelli RMB, Silva MTAD, Garcia JF. Satellyptus: Analysis and database of microsatellites from ESTs of Eucalyptus. Genet Mol Biol 2005;28:589-600 47572005000400014

https://doi.org/10.1590/S1415-

27. Rabello E, Souza AND, Saito D, Tsai SM. In silico characterization of microsatellites in Eucalyptus spp: abundance length variation and transposon associations. Genet Mol Biol. 2005;28:582-88. https://doi.org/10.1590/S1415-47572005000400013

28. Yasodha R, Sumathi R, Chezhian P, Kavitha S, Ghosh M. Eucalyptus microsatellites mined in silico: survey and evaluation. J Genet. 2008;87:21-25 https://doi.org/10.1007/s12041-008-0003-9

29. Dasgupta MG, Dharanishanthi V, Agarwal I, Krutovsky KV. Development of genetic markers in Eucalyptus species by target enrichment and exome sequencing. PloS one. 2015; 10:e0116528.

https://doi.org/10.1371/journal.pone.0116528

30. Andrade MC, Perek M, Pereira FB, Moro M, Tambarussi EV Quantity, organization, and distribution of chloroplast microsatellites in all species of Eucalyptus with available plastome sequence. Crop Breed Appl Biotechnol. 2018; 18:97102. https://doi.org/10.1590/1984-70332018v18n1a13

31. Jhanwar S, Priya P, Garg R, Parida SK, Tyagi AK, Jain M. Transcriptome sequencing of wild chickpea as a rich resource for marker development. Plant Biotechnol J. 2012; 10:690-702. https://doi.org/10.1111/j.1467-7652.2012.00712.x

32. Duran C, Singhania R, Raman H, Batley J, Edwards D Predicting polymorphic EST-SSRs in silico. Mol Ecol Resour. 2013; 13:538-45. https://doi.org/10.1111/1755-0998.12078

33. Motta FG, Skowronski L, da Costa JV, da Costa RB. Transferability of microsatellite loci from Croton floribundus Spreng. to Croton urucurana Baill. (Euphorbiaceae). Afr Biotechnol. 2019 https://doi.org/10.5897/AJB2019.16810

34. Nagel JH, Cruywagen EM, Machua J, Wingfield MJ, Slippers B. Highly transferable microsatellite markers for the genera Lasiodiplodia and Neofusicoccum. Fungal Ecol. 2020; 44:100903. https://doi.org/10.1016/j.funeco.2019.100903

35. Voorrips RE. MapChart: software for the graphical presentation of linkage maps and QTLs. J Hered. 2002;93:77-78. https://doi.org/10.1093/jhered/93.1.77 
36. Rozen S, Skaletsky H. Primer3 on the WWW for general users and for biologist programmers. In: Bioinformatics methods and protocols 2000 (pp. 365-386). Humana Press, Totowa, NJ https://doi.org/10.1385/1-59259-192-2:365

37. Cao Y, Wang L, Xu K, Kou C, Zhang Y, Wei G, He J, Wang Y, Zhao L. Information theory-based algorithm for in silico prediction of PCR products with whole genomic sequences as templates. BMC bioinformatics. 2005; 6:190. https://doi.org/10.1186/1471-2105-6-190

38. Peakall R, Gilmore S, Keys W, Morgante M, Rafalski A. Cross species amplification of soybean (Glycine max) simple sequence repeats (SSRs) within the genus and other legume genera: implications for the transferability of SSRs in plants. Mol Biol Evol. 1998;15:1275-87. https://doi.org/10.1093/oxfordjournals.molbev.a025856

39. Acuña CV, Villalba PV, García M, Pathauer P, Hopp HE, Marcucci Poltri SN. Microsatellite markers in candidate genes for wood properties and its application in functional diversity assessment in Eucalyptus globulus. Electron J Biotechnol. 2012; 15(2):1-17. https://doi.org/10.2225/vol15-issue2-fulltext-3
40. Bradbury D, Smithson A, Krauss SL. Development and testing of new gene-homologous EST-SSRs for Eucalyptus gomphocephala (Myrtaceae). Appl Plant Sci. 2013;1:1300004 https://doi.org/10.3732/apps.1300004

41. Bayly MJ, Rigault P, Spokevicius A, Ladiges PY, Ades PK, Anderson C, Bossinger G, Merchant A, Udovicic F, Woodrow IE, Tibbits J. Chloroplast genome analysis of Australian eucalypts Eucalyptus, Corymbia, Angophora, Allosyncarpia and Stockwellia (Myrtaceae). Mol Phylogenetics Evol. 2013;69:70416. https://doi.org/10.1016/j.ympev.2013.07.006

42. Steane DA. Complete nucleotide sequence of the chloroplast genome from the Tasmanian blue gum Eucalyptus globulus (Myrtaceae). DNA Res. 2005;12:215-20. https://doi.org/10.1093/dnares/dsi006

43. Paiva JA, Prat E, Vautrin S, Santos MD, San-Clemente $H$, Brommonschenkel S, Fonseca PG, Grattapaglia D, Song X, Ammiraju JS, Kudrna D. Advancing Eucalyptus genomics: identification and sequencing of lignin biosynthesis genes from deep-coverage BAC libraries. BMC genomics. 2011;12:137. https://doi.org/10.1186/1471-2164-12-137 